\title{
Pulmonary Vein Obstruction
}

National Cancer Institute

\section{Source}

National Cancer Institute. Pulmonary Vein Obstruction. NCI Thesaurus. Code C111651.

Blockage of the lumen of the pulmonary vein. 